\title{
Alcalose ruminal e pneumonia por aspiração de conteúdo ruminal em ovino: relato de caso
}

Gilson Antonio Pessoa", Daniel Fantinel Rodrigues, Jerbeson Hoffmann da Silva, Vanessa de Lima, Milana Paese, Elisa Nappi

Biasin, Guilherme Novello

Universidade de Caxias do Sul (UCS), Caxias do Sul, RS, Brasil

*Autor correspondente

e-mail: gilsonpessoavet@yahoo.com.br

\section{Resumo}

A busca por uma produtividade cada vez mais elevada, muitas vezes dispondo de pequenas áreas, ou mesmo o baixo teor proteico de determinadas variedades forrageiras, implica na utilização de suplementos proteicos ou fertilizantes nitrogenados como forma de suprir tais necessidades. 0 consumo excessivo destes suplementos proteicos, ou ainda seu consumo por animais não adaptados, pode levar a um quadro de intoxicação aguda, caracterizado por incoordenação motora, tremores musculares, colapso e morte. Foi atendido no hospital de grandes animais do curso de Medicina Veterinária da Universidade de Caxias do Sul, um ovino macho SRD, pesando $53 \mathrm{~kg}$, com idade aproximada de 3 anos e utilizado como reprodutor. 0 histórico era de alcalose ruminal, com acometimento de outros animais no mesmo rebanho, sendo que alguns destes vieram a óbito. Devido a isso, o paciente estava anoréxico, apático, desidratado, com atonia ruminal, frequente regurgitação de conteúdo indigerido e havia desenvolvido um quadro de pneumonia, secundário ao quadro inicial de intoxicação por ureia. 0 tratamento iniciado na data de internação foi baseado no uso de antibioticoterapia, dipirona, mucoliticos e protetores hepáticos. Posteriormente, realizou-se a fluidoterapia no intuito de corrigir o balaço hidroeletrolítico observado. Com a realização do aspirado traqueal, para se determinar a causa e a etiologia do quadro de pneumonia observado, constatouse ser decorrente da aspiração do conteúdo ruminal. Com o objetivo de determinar o motivo da constante regurgitação observada, optou-se inicialmente pela passagem de uma sonda oroesfofágica. Com isso, foi possível observar grande quantidade de conteúdo ruminal, com odor pútrido e inatividade da flora ruminal. Além disso, foi recuperado um pedaço de uma sacola plástica, a qual poderia estar causando uma obstrução, resultando na constante regurgitação apresentada. Na tentativa de remover o conteúdo ruminal, bem como buscar outros possíveis corpos estranhos presentes no rúmen, o animal foi submetido à ruminotomia. Foi realizada sedação com xilazina $2 \%(0,1 \mathrm{mg} / \mathrm{kg}$ IV) e anestesia local com lidocaína $2 \%$ com vasoconstritor 
para a realização do bloqueio local em "L" invertido. Durante o esvaziamento do rúmen, nenhum corpo estranho adicional foi encontrado e o conteúdo ruminal foi totalmente removido. Adicionalmente foi realizada transfusão de líquido ruminal a partir de um animal hígido. No pós operatório foi aplicado enrofloxacino 10\% (2,5mg/kg I.M.) durante 6 dias e Flunixin Meglumine (1.1mg/kg I.M.) durante 3 dias. 0 animal teve alta após 15 dias internado e apresentou desempenho reprodutivo satisfatório. Em conclusão, uma falha de manejo na propriedade levou a um quadro de intoxicação aguda por ureia, o qual foi tratado na propriedade; adicionalmente, a estase ruminal levou à pneumonia por aspiração do conteúdo ruminal, ocasionada pela constante regurgitação devido à presença de um corpo estranho no rúmen. 